\title{
Review of Living on the Spectrum: Autism and Youth in Community by Elizabeth Fein
}

\author{
Laura Sterponi \\ University of California, Berkeley, CA, USA
}

Elizabeth Fein's Living on the Spectrum: Autism and Youth in Community (2020), offers an original and nuanced examination of current debates about autism. No longer understood solely as a nosological entity - in fact, already quite complicated and elusive as a psychiatric category, given the important changes in diagnostic nomenclature and criteria introduced in the fifth edition of the Diagnostic and Statistical Manual of Mental Disorders (DSM-5; American Psychiatric Association, 2013) - autism is also a shifting cultural phenomenon and a topic of ongoing public contention. Fein illuminates the epistemological underpinnings and political agendas of coexisting and conflicting discourses of autism, mobilizing effectively conceptual tools from a range of theoretical traditions, notably anthropology (in a few of its specializations) and critical disability studies. Her analysis, however, starts from and remains anchored in the everyday experiences and vicissitudes of the people directly affected by autism spectrum conditions, to which she had access through her two-year multisite ethnographic fieldwork.

Fein immersed herself as participant-observer in a variety of contexts - summer camps, schools, support groups, science fiction conventions, medical school clinics, and research associations' meetings. Known as clinical ethnography, her fieldwork was informed by anthropological training (Fein received her $\mathrm{PhD}$ from the Department of Comparative Human Development at the

karger@karger.com

(c) 2021 S. Karger AG, Basel

www.karger.com/hde

Karger!
University of Chicago) as well as training in psychodynamic psychotherapy and neurodevelopmental assessment. Thus, her investigation attended to the subjective experience as well as to cultural processes.

Fein situates autism at the intersection of the individual and the sociocultural, the person and the world, cleverly pointing out an inherent paradox in the mainstream, biomedical characterization of the condition, which posits insular detachment while, Fein argues, "other people ... and other things ... are always a constitutive component of autism" (p. 6). She invites considering, for instance, how deficits in social-emotional reciprocity, included in the DSM-5 diagnostic criteria, by definition involve relationship and others. "It takes (at least) two to tango", Fein contends (p. 6), her argument lending affinities with autistic scholar Damian Milton. In discussing the ontological status of autism, Milton (2012) has theorized the "double empathy problem" arguing that "it is true that autistic people often lack insight about nonAS perceptions and culture, yet it is equally the case that non-AS people lack insight into the minds and culture of 'autistic people"' (p. 886).

Another DSM-5 autism spectrum disorders' diagnostic criterion insightfully unpacked in this monograph is "highly restricted, fixated interests that are abnormal in intensity and focus" (American Psychiatric Association, 2013). Fein situates this proclivity beyond the individual, 
documenting how it manifests in practices that are inherently social and cultural. She documents youth on the spectrum's fervent engagement in live action role playing, in which they perform characters with magical powers, moving along narrative trajectories that enact mythological themes. Through cultivating such passionate interests, autistic people demonstrate a deep involvement with cultural materials and communities - from transhistorical archetypes to transnational fandoms - and Fein's analysis unearths the developmental affordances of role play and storytelling, which support autistic youth in integrating the manifold aspects of their being, their strengths as well as their vulnerabilities.

Fein's ethnographic account is richly textured, with contextual details and excerpts of conversation that transport the reader into the reported events and encounters. These ethnographic descriptions not only demonstrate Fein's perceptive gaze, but also her deep interpersonal engagement with the individuals who participated in her research. While never didactic, Fein's ethnographic writing has instructional value, providing a clear demonstration of what it means and how one goes about doing participant observation.

Fein's monograph is equally nuanced and instructive when it tackles the politics of autism and neurodiversity activism, documenting the neurodevelopmental turn, with its emphasis on the structural wiring of the brain. Fein is not shy in aligning with scholars and activists who advocate a strong rejection of the deficit model of autism and petition for understanding the condition as manifes- tation of neural diversity. Joining a handful of other scholars, notably philosopher Catherine Malabou (2008) and sociologist Victoria Pitts-Taylor (2010), however, Fein cautions against reductionism nested in certain neurodiscourses, as well as neoliberal undercurrents in discourses of neurological self-fashioning (p. 129).

Living on the Spectrum is written in an engaging, clear, and at times poetic style, which augments the monograph's accessibility beyond academic readership. Within academia, the book is relevant for scholars interested in autism across disciplines. It would be a stimulating reading in graduate seminars as well as upper-level undergraduate courses in medical and psychological anthropology, cultural and disability studies, developmental psychopathology, and human development.

\section{Statement of Ethics}

No ethical approval was required for the preparation of this manuscript, as no human or animal subjects were used.

\section{Conflict of Interest Statement}

The author has no conflicts of interest to declare.

\section{Funding Sources}

No external funding was received for this paper.

\section{References}

American Psychiatric Association (2013). Diagnostic and statistical manual of mental disorders (5th ed.). American Psychiatric Association.

Fein, E. (2020). Living on the spectrum: Autism and youth in community. NYU Press. https://doi. org/10.18574/nyu/9781479864355.001.0001

Malabou, C. (2008). What should we do with our brains? Fordham University Press.
Milton, D. (2012). On the ontological status of autism: The "double empathy problem." Disability \& Society, 27(6), 883-887. https://doi.org/ $10.1080 / 09687599.2012 .710008$

Pitts-Taylor, V. (2010). The plastic brain: Neoliberalism and the neuronal self. Health, 14(6), 635-652. https://doi.org/10.1177/ 1363459309360796 